\title{
Molecular Imaging of Monocrotaline-Induced Pulmonary Vascular Disease with Radiolabeled Linear Adrenomedullin
}

\author{
Jocelyn Dupuis ${ }^{1,2}$, François Harel ${ }^{1,3}$, Yan $\mathrm{Fu}^{4}$, Quang Trinh Nguyen ${ }^{1}$, Myriam Letourneau ${ }^{4}$, Annick Préfontaine ${ }^{1}$, \\ and Alain Fournier ${ }^{4}$ \\ ${ }^{1}$ Research Center, Montreal Heart Institute, University of Montreal, Montreal, Quebec, Canada; ${ }^{2}$ Department of Medicine, \\ University of Montreal, Montreal, Quebec, Canada; ${ }^{3}$ Department of Radiology, University of Montreal, Montreal, Quebec, Canada; \\ and ${ }^{4}$ Institut National de la Recherche Scientifique-Institut Armand Frappier, Laval, Quebec, Canada
}

\begin{abstract}
No test currently exists for molecular imaging of pulmonary arterial hypertension (PAH). Adrenomedullin is a vasodilator peptide predominantly cleared by pulmonary endothelial receptors. We developed a linear adrenomedullin derivative radiolabeled with ${ }^{99 m}$ Tc $\left({ }^{99 m}\right.$ Tc-AM-L) for imaging of pulmonary circulation and tested its capacity to detect anomalies of pulmonary circulation caused by PAH. Methods: PAH was induced by monocrotaline in rats and compared with controls. After $5 \mathrm{wk}$, ${ }^{99 m T C-A M-L}$ was injected intravenously. Plasma kinetics were measured, lung activity was determined in vivo after 30 min using a nuclear camera, and lung activity was determined ex vivo in explanted lungs. Expression of adrenomedullin receptors was measured in lung homogenates. Results: The plasma levels of $99 \mathrm{mTC}$ AM-L significantly increased in PAH by approximately 2 -fold. Uptake by the lungs was homogeneous but greatly reduced in $\mathrm{PAH}$ by about $70 \%$. In vivo retention was $14 \% \pm 1 \%$ (mean \pm $\mathrm{SD})$ of the injected dose in controls and $4 \% \pm 1 \%$ in $\mathrm{PAH}(P<$ $0.0001)$. A similar reduction was measured ex vivo (6.0 \pm 1.6 percentage injected dose per gram [\%ID/g] vs. $0.95 \pm 0.21 \% \mathrm{ID} / \mathrm{g}$, $P<0.0001)$. The expression of the heterodimeric component of the adrenomedullin receptor, receptor activity modifying protein 2 , was also greatly reduced in PAH lungs $(P<0.001)$. Interestingly, right ventricular uptake of $99 \mathrm{mTC}-\mathrm{AM}-\mathrm{L}$ was increased by $\mathrm{PAH}(P=0.02)$ and correlated with the degree of right ventricular hypertrophy $(r=0.83, P=0.001)$. Conclusion: Pulmonary uptake of ${ }^{99 \mathrm{~m} T C-A M-L}$ is greatly reduced in monocrotaline-induced $\mathrm{PAH}$. This novel molecular imaging agent may be useful in the diagnosis and follow-up of pulmonary vascular disorders.
\end{abstract}

Key Words: diagnosis; pulmonary hypertension; imaging; lung; nuclear medicine

J Nucl Med 2009; 50:1110-1115

DOI: 10.2967/jnumed.108.059428

N. o clinically available test currently exists that can provide both anatomic and functional information on the

Received Oct. 21, 2008; revision accepted Mar. 9, 2009.

For correspondence or reprints contact: Jocelyn Dupuis, Research Center, Montreal Heart Institute, 5000 Bélanger St., Montreal, Quebec,

Canada, H1T $1 \mathrm{C} 8$.

E-mail: jocelyn.dupuis@bellnet.ca

COPYRIGHT $\odot 2009$ by the Society of Nuclear Medicine, Inc. status of pulmonary circulation. Pulmonary arterial hypertension (PAH) is a disorder characterized by endothelial dysfunction, with intimal and vascular smooth muscle proliferation leading to gradual obliteration of pulmonary arterioles (1). PAH is screened by transthoracic Doppler echocardiography, with the estimation of pulmonary artery systolic pressure obtained using the tricuspid valve regurgitant jet. Although this approach correlates with hemodynamically measured pulmonary pressure, it does not provide direct information on the biology of pulmonary circulation and may miss the early presence of pulmonary vascular disease (1). The recent availability of oral therapies for PAH such as endothelin receptor antagonists and phophodiesterase inhibitors advocates for earlier diagnosis of this condition and treatment of subjects in functional class II (1). There is, therefore, a clinical need for novel diagnostic approaches toward pulmonary vascular disease that could provide an earlier and more precise diagnosis.

Adrenomedullin is a vasodilator peptide produced by the vascular endothelium. When injected intravenously, adrenomedullin is predominantly cleared by pulmonary circulation by specific adrenomedullin receptors $(2,3)$. Human and rat lungs indeed contain a high density of specific adrenomedullin binding sites $(4,5)$, mostly distributed on the vascular endothelium. We hypothesized that PAH would be associated with reduced density of adrenomedullin receptors, which could be measured using an externally detectable tagged receptor substrate. To that aim, we developed a linear human adrenomedullin derivative enabling direct labeling with ${ }^{99 \mathrm{~m}} \mathrm{Tc}$ ( $\left.{ }^{99} \mathrm{~m} \mathrm{Tc}-\mathrm{AM}-\mathrm{L}\right)$ and recently demonstrated the capacity of this agent to specifically bind to lung adrenomedullin receptors, thus enabling the imaging of pulmonary circulation and the detection of large perfusion defects (6). We also demonstrated that linear adrenomedullin specifically binds to human MCF-7 cells expressing adrenomedullin receptors (6). The rat lungs contained a high density of specific adrenomedullin binding sites (dissociation constant, $0.66 \mathrm{nM}$; maximum number of binding sites, $1,760 \mathrm{fmol} / \mathrm{mg}$ protein) (7). In the current study, we tested 
the capacity of this novel molecular imaging method to detect abnormalities of pulmonary circulation caused by monocrotaline-induced PAH in rats.

\section{MATERIALS AND METHODS}

All experimental procedures were performed in accordance with regulations and ethical guidelines from the Canadian Council for the Care of Laboratory Animals and received approval by the animal ethics and research committee of the Montreal Heart Institute.

\section{Linear Adrenomedullin (AM-L) Synthesis and Purification}

Human adrenomedullin is a cyclic 5-amino-acid peptide comprising 2 cysteine residues located at positions 16 and 21 from the $\mathrm{N}$ terminus. The 2 cysteine residues are bound by disulfide linkage, forming a ring composed of 6 amino acids. The AM-L derivative used in the present study has the same structure, except that it lacks a rink by omission of the disulfide linkage. The complete 52-amino-acid sequence of adrenomedullin was synthesized using a solid-phase procedure based on fluorenylmethyloxycarbonyl chemistry, with a rink-adrenomedullin-amide resin (Chem-Impex International) as the solid support.

The crude linear adrenomedullin was purified without performing an oxidation step, which would result in the disulfide bond formation to preserve free cysteine residues necessary to achieve the radiolabeling.

The purity of the collected fractions was evaluated through analytic reversed-phase high-performance liquid chromatography, and the mass was established with matrix assisted laser desorption/ionization time-of-flight mass spectrometry (Voyager DE; Applied Biosystems). Homogeneous fractions corresponding to the linear form of the peptide (AM-L) were then pooled and separated into 2.9-nmol samples, before lyophilization.

\section{Radiolabeling and Purification}

Sample vials containing $2.9 \mathrm{nmol}$ of AM-L were kept at $-20^{\circ} \mathrm{C}$. Radiolabeling was performed by adding to the vial $100 \mu \mathrm{L}$ of $\mathrm{HCl}$ $(1 \mathrm{mmol} / \mathrm{L})$ and $14.8 \mu \mathrm{L}$ of $\mathrm{SnCl}_{2} \cdot 2 \mathrm{H}_{2} \mathrm{O}(0.2 \mathrm{mg} / \mathrm{mL}$ [13 nmol]). Immediately after the material had dissolved, $555 \mathrm{MBq}(15 \mathrm{mCi})$ of freshly prepared $\mathrm{Na}^{99 \mathrm{~m}} \mathrm{TcO}_{4}(28.9 \mathrm{pmol})$ in saline solution was added, and the mixture was kept at room temperature for $1 \mathrm{~h}$. After the radiolabeling step, $1 \mathrm{~mL}$ of phosphate-buffered saline (PBS) ( $\mathrm{pH}$ 7.4) was added to the solution.

All of the ${ }^{99 \mathrm{~m}} \mathrm{Tc}-\mathrm{AM}-\mathrm{L}$ reaction mixture was injected onto a 1-mL (100-mg) C18 Sep-Pak (Waters) cartridge. The cartridge was then washed with $3 \mathrm{~mL}$ of hydrochloric acid $(1 \mathrm{mmol} / \mathrm{L})$ and eluted with $3 \mathrm{~mL}$ of a $50 \%$ ethanol solution. Fractions of $0.5 \mathrm{~mL}$ were collected into sterile polypropylene tubes. Fractions and cartridge radioactivity count were then measured, and the 3 fractions with the highest counts were pooled. A total of $200 \mu \mathrm{L}$ of $10 \times$ sterile PBS ( $\mathrm{pH}$ 7.4) was added, and the radiochemical purity-as measured using instant thin-layer chromatography-silica gel strips (PALL Life Sciences)—was greater than or equal to $95 \%$.

\section{Studies in Monocrotaline-Induced PAH}

Male Sprague-Dawley rats (Charles River) weighing between $200 \mathrm{~g}$ and $225 \mathrm{~g}$ received a $0.5-\mathrm{mL}$ intraperitoneal injection of either $0.9 \%$ saline $(n=8)$ or $60 \mathrm{mg}$ of monocrotaline per kilogram $(n=11)$. Five weeks later, rats were anesthetized for hemodynamic measurements using microtip pressure transducer catheters (model SPR-407, 2F; Millar Instruments).

Nuclear Medicine Experiments. The animals were anesthetized by an initial intramuscular dose of xylazine $(10 \mathrm{mg} / \mathrm{kg})$ and ketamine $(50 \mathrm{mg} / \mathrm{kg})$, followed by an intraperitoneal injection of heparin (2,000 U; Sigma Chemical Co.). Additional doses of xylazine and ketamine were used if noxious stimuli (hind feet pinching) could elicit nociceptive motor reflexes or changes of the systemic blood pressure.

${ }^{99 \mathrm{~m}} \mathrm{Tc}-\mathrm{AM}-\mathrm{L}$ was injected in a volume of $200 \mu \mathrm{L}(0.3 \mathrm{pmol}$, $18.5 \mathrm{MBq}[0.5 \mathrm{mCi}])$ into the right jugular vein. A series of 200$\mu \mathrm{L}$ blood samples was collected at 1 and $3 \mathrm{~min}$ after the initial adrenomedullin injection, then repeated every $5 \mathrm{~min}$ for a 30-min period. After each sample collection, an equal volume of saline was injected into the animal to maintain blood volume and pressure.

The whole-body biodistribution of radiolabeled peptide was evaluated using 2 different approaches: in vivo by imaging with a nuclear camera and ex vivo by surgically removing and counting organs in a $\gamma$-counter. In vivo multiorganic biodistribution of ${ }^{99 \mathrm{~m}} \mathrm{Tc}-\mathrm{AM}-\mathrm{L}$ was evaluated with a signature camera system (E.Cam; Siemens) equipped with an on-board computer and a low-energy, high-resolution parallel-hole collimator. Images were acquired using a $256 \times 256$ matrix with a pixel size of $1.35 \mathrm{~mm}$. The syringe containing labeled AM-L was counted before injection using 1 head of the $\gamma$-camera. To determine attenuation, the animal was scanned from the top with 1 camera head, and a flood source was placed underneath. After the dose injection, images in anterior and posterior views were obtained using the 2 camera heads. The quantity of tracer remaining in the syringe was then measured and subtracted to determine the injected dose. Regions of interest (ROI) were manually drawn over whole organs (lungs, heart, liver, bladder, kidneys, gallbladder) by an experienced technician. Background ROIs were drawn next to those organs.

After intravenous injection of ${ }^{99 \mathrm{~m} T c-A M-L}$, dynamic acquisition was recorded for a 30-min period (1 frame per second during the first minute, then 1 frame per minute for the remaining time). Static acquisitions were also recorded for whole individual organs, including the lungs, kidneys, liver, heart, and bladder at $30 \mathrm{~min}$ after initial injection. Biodistribution for each organ was computed in percentage injected dose (\%ID). All images were compensated for ${ }^{99 \mathrm{~m} T c}$ half-life. Background activity was removed from the anterior and posterior activity of each organ by extrapolating on the size of the ROI. Geometric means of anterior and posterior activity were computed for each organ and compensated for mean attenuation of that organ.

At the end of in vivo acquisition, the animals were sacrificed and the lungs, liver, kidneys, and heart (separated into right ventricle and left ventricle plus septum) were removed, gravitydrained, and weighed. The blood samples and organs were then placed in a $\gamma$-counter (model 1470 Wizard; Wallac) to determine ${ }^{99 \mathrm{~m}} \mathrm{Tc}$ activity. Results were expressed as a \% ID per gram $(\% \mathrm{ID} / \mathrm{g})$ of organ weight.

\section{Adrenomedullin Receptor Expression}

To determine the level of expression of adrenomedullin receptors in the lungs of control and monocrotaline-treated animals, we performed Western immunoblots directed at the receptor activity modifying protein 2 (RAMP2), the accessory protein associated with adrenomedullin receptors found in lung tissues. To perform lung protein extraction, the snap-frozen right inferior lobe was 
homogenized using a polytron homogenizer in lysis buffer containing a protease inhibitor cocktail. The homogenate was clarified by centrifugation, and the final protein concentration was determined. Fifty micrograms of protein per sample were separated on a $15 \%$ sodium dodecylsulfonate-polyacrylamide gel electrophoresis gel for $1 \mathrm{~h}$ at $200 \mathrm{~V}$ at $4^{\circ} \mathrm{C}$ and transferred onto a polyvinylidene difluoride membrane at $100 \mathrm{~V}$ for $90 \mathrm{~min}$ at $4^{\circ} \mathrm{C}$. The membrane was subsequently blocked for $2 \mathrm{~h}$ at room temperature with 5\% skimmed milk powder in PBS $1 \times$ and $0.01 \%$ polysorbate 20 (PBS-T) and incubated overnight at $4{ }^{\circ} \mathrm{C}$ with primary rabbit polyclonal antibody raised against amino acids 28-166 of RAMP2 of human origin (Santa Cruz). The antibody was diluted 1:500 with 5\% milk in PBS-T overnight at $4^{\circ} \mathrm{C}$. The membrane was then washed with PBS-T, reblocked for 10 min with 5\% milk diluted in PBS-T, and then incubated with the appropriate horseradish peroxidase-conjugated secondary antibody for rabbit (Jackson Laboratories) diluted 1:10,000 in 5\% milk PBS-T. After 3 washes, the immunoreactive bands were visualized by enhanced chemiluminescence (Renaissance Plus; Perkin Elmer Life Sciences) according to the manufacturer's instructions using Bio-Max MR film. Anti-actin $(1: 1,000)$ antibody was used to ensure equal protein loading.

\section{Hemodynamic Measurements}

Male Sprague-Dawley rats $(n=3)$ weighing 200-225 g were anesthetized with $3 \%(\mathrm{v} / \mathrm{v})$ isoflurane in $100 \% \mathrm{O}_{2}$. The right jugular vein was then isolated and incised, and a polyethylene catheter (PE 50; Instech Solomon) was inserted in the right atrium for bolus intravenous injection. A microtip pressure transducer catheter (Millar Instruments) was inserted into the right carotid artery for hemodynamic recording. During a period of stabilization $(\sim 30 \mathrm{~min})$, isoflurane was reduced to $1.5 \%$. The signal for systemic arterial blood pressure and heart rate were recorded on a personal computer via an analog-to-digital converter (PowerLab; ADInstruments). Either saline $(0.7 \mathrm{~mL} / \mathrm{kg})$, AM-L (2.9 nmol, equivalent to 10 times the injected dose for imaging studies), or isoproterenol $(10 \mathrm{ug} / \mathrm{kg})$ were injected successively into the right jugular vein, and hemodynamic measurements were monitored.

\section{Statistical Analysis}

Differences between groups were evaluated by 2-tailed independent sample $t$ tests. Plasma kinetics of ${ }^{99 \mathrm{~m}}$ Tc-AM-L were analyzed using a 2-compartment pharmacokinetic model with Prism software (version 4.0; GraphPad), and the fitted curves were compared using an F test. All values are reported as mean $\pm \mathrm{SD}$.

\section{RESULTS}

Severe PAH developed in monocrotaline-treated rats with a right ventricular systolic pressure of $88 \pm 26 \mathrm{~mm}$ $\mathrm{Hg}(n=11)$, compared with $30 \pm 7 \mathrm{~mm} \mathrm{Hg}(n=8)$ in controls $(P<0.001)$. There was also important right ventricular hypertrophy evidenced by a higher right-to-left ventricular plus septum weight ratio of $0.50 \pm 0.07$, compared with $0.22 \pm 0.07(P<0.001)$.

The plasma kinetics of ${ }^{99 \mathrm{~m}} \mathrm{Tc}-\mathrm{AM}-\mathrm{L}$ are presented in Figure 1 . The fitted curves were significantly different $(P<$ 0.001 ), with plasma levels approximately 2-fold higher in PAH than in control animals. After $10 \mathrm{~min}$, levels were

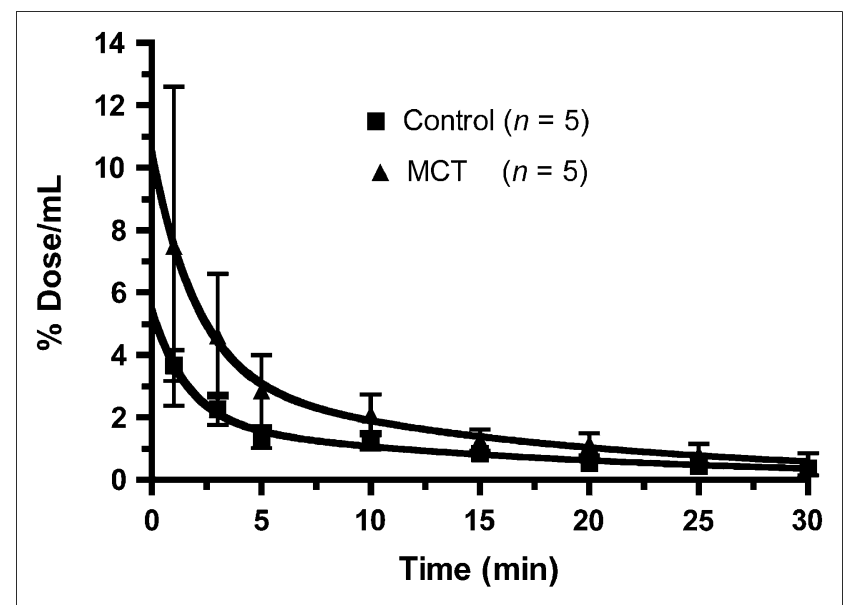

FIGURE 1. Plasma kinetics of $99 \mathrm{mTC}-\mathrm{AM}-\mathrm{L}$ in control group and in monocrotaline-induced PAH (MCT) group. Fitted 2-compartment-model curves are significantly different, with a $P$ value less than 0.001 .

$1.25 \pm 0.28 \%$ ID in controls, compared with $2.08 \pm 0.65$ $\%$ ID in PAH animals $(P=0.03)$.

The biodistribution of ${ }^{99 \mathrm{~m} T c-A M-L} 30 \mathrm{~min}$ after injection was determined by 2 different approaches: in vivo using a nuclear camera (Fig. 2) and ex vivo by counting the explanted organs in a $\gamma$-counter (Fig. 3). The in vivo biodistribution revealed a markedly reduced lung uptake of the tracer from $14 \pm 1 \%$ ID in controls to $4 \pm 1 \%$ ID in PAH $(P<0.0001)$. A similar important reduction was observed ex vivo with $6.0 \pm 1.6 \% \mathrm{ID} / \mathrm{g}$ versus $0.95 \pm$ $0.21 \% \mathrm{ID} / \mathrm{g}(P<0.0001)$. The monocrotaline-treated group also demonstrated increased liver uptake but lower kidney and bladder activities than did the control group. Interestingly, although the heart displayed little retention of this molecular imaging agent, the uptake as measured ex vivo was increased in the PAH animals from $0.14 \pm 0.02 \% \mathrm{ID} / \mathrm{g}$

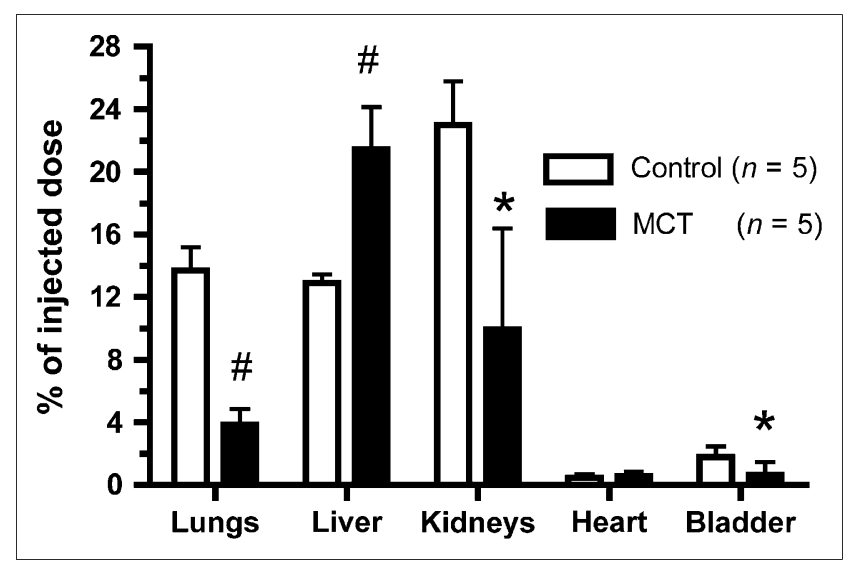

FIGURE 2. In vivo biodistribution of $99 \mathrm{mTC}-\mathrm{AM}-\mathrm{L}$ in control group and in monocrotaline-induced PAH (MCT) group. ${ }^{\#} P<$ 0.001 vs. control. ${ }^{\star} P<0.05$ vs. control. 


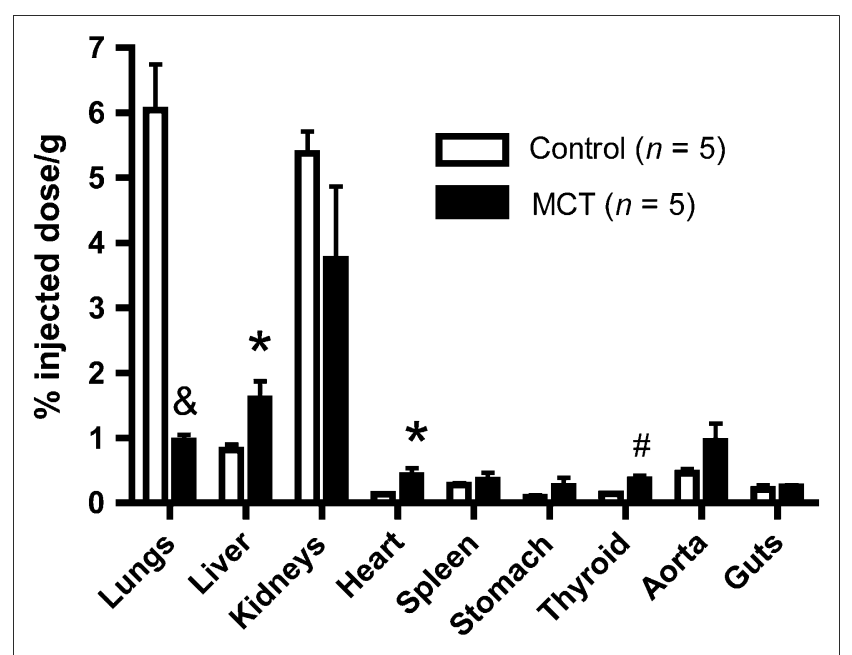

FIGURE 3. Ex vivo biodistribution of $99 \mathrm{mTC}-A M-L$ in control group and in monocrotaline-induced PAH (MCT) group. $\& P<0.001$ vs. control. ${ }^{*} P<0.05$ vs. control. ${ }^{\#} P<0.01$ vs. control.

to $0.43 \pm 0.24 \% \mathrm{ID} / \mathrm{g}(P<0.05)$. The increased uptake in the right heart ventricle correlated with right ventricular weight $(r=0.83, P<0.01)$, although no correlation for the left ventricle plus septum was shown $(r=-0.58)$.

Whole-body images of rats $30 \mathrm{~min}$ after injection are presented in Figure 4. Homogeneous bilateral lung uptake in control rats and a marked reduction of ${ }^{99 \mathrm{~m}} \mathrm{Tc}-\mathrm{AM}-\mathrm{L}$ in

Control

$\mathrm{PAH}$

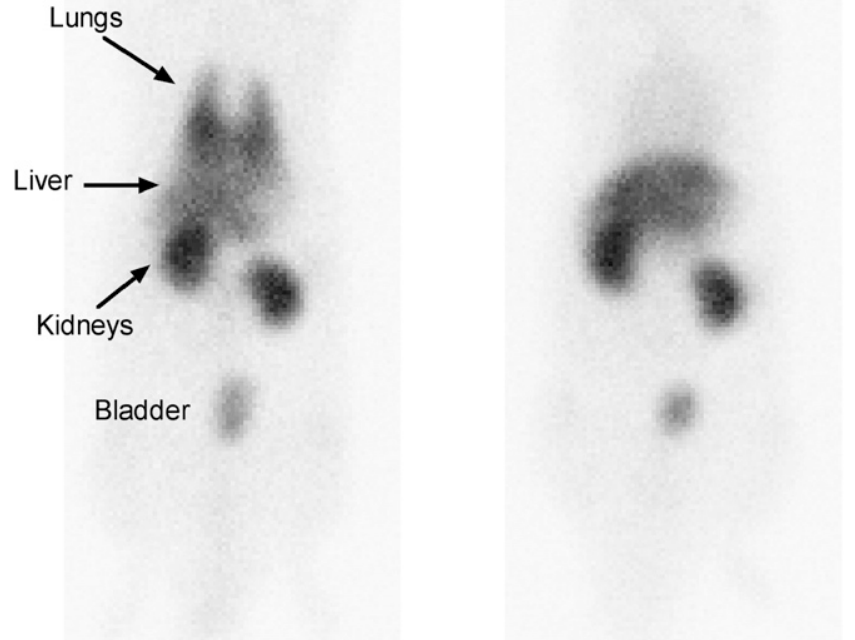

FIGURE 4. Whole-body scans $30 \mathrm{~min}$ after intravenous 99mTc-AM-L injection in control and PAH model animals. the animals with PAH (barely any lung uptake was visible) were observed. Dynamic imaging revealed that lung uptake occurred rapidly within the first lung transit time and was maintained for $30 \mathrm{~min}$ in controls; no evident lung tracer uptake was seen in the PAH group (Supplemental Video 1; supplemental materials are available online only at http:// jnm.snmjournals.org).

The heterodimeric adrenomedullin receptor component RAMP2 was evaluated in lung tissue by Western immunoblots. There was a marked reduction of RAMP2 protein expression (Fig. 5) in PAH rats $(P<0.001)$.

Studies in anesthetized rats revealed that AM-L injection in doses representing 10 times the amount used for lung imaging in this study did not cause any detectable variation in blood pressure or heart rate.

\section{DISCUSSION}

Adrenomedullin is a multifunctional peptide mostly expressed in endothelial cells and distributed in various tissues, such as the lung, kidney, and heart $(3,5)$. Previous studies have observed a high density of binding sites for adrenomedullin, with high affinity in lung tissues $(4,5)$, which act as clearance receptors for the peptide $(3,6)$. In rat lungs, these specific binding sites have been pharmacologically characterized through binding studies with dissociation constant and maximum number of binding site values of $0.66 \mathrm{nmol}$ and $1,760 \mathrm{fmol} / \mathrm{mg}$, respectively (7). Moreover, it has been shown that adrenomedullin binding in rat lungs can be antagonized by adrenomedullin (22-52) but not by calcitonin gene-related peptide (8-37), a pharmacologic profile associated with the calcitonin receptorlike receptor (CLR)-RAMP 2 receptor complex (8). Furthermore, intravenous injection of rat ${ }^{125} \mathrm{I}$-adrenomedullin in Sprague-Dawley rats showed a rapid distribution of the

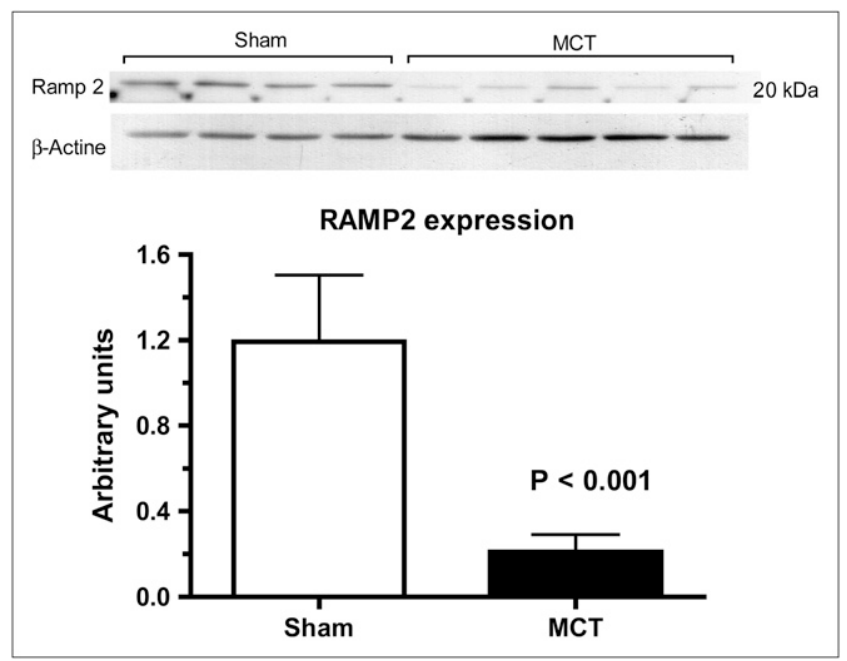

FIGURE 5. Lung tissue protein expression of AM receptor component RAMP2 in sham and monocrotaline-induced $\mathrm{PAH}$ (MCT) rats. 
peptide, with the lungs retaining most of the radioactive tracer. The specificity of lung binding with this tracer was even confirmed by displacement with unlabeled rat adrenomedullin (3). Furthermore, we have recently demonstrated that ${ }^{99 \mathrm{~m}} \mathrm{Tc}-\mathrm{AM}-\mathrm{L}$ specifically binds to human MCF-7 cells expressing adrenomedullin receptors (6).

We used ${ }^{99 \mathrm{~m}} \mathrm{Tc}-\mathrm{AM}-\mathrm{L}$ for the imaging of pulmonary circulation and tested its ability to detect the abnormal pulmonary circulation in a model of PAH. We demonstrated that this molecular imaging agent can be used to detect abnormalities of pulmonary microcirculation. In PAH, lung uptake of ${ }^{99 \mathrm{~m} T c-A M-L}$ was markedly reduced. $\mathrm{PAH}$ is a disorder characterized by medial hypertrophy of pulmonary arterioles with intimal proliferation, leading to obliteration and loss of pulmonary circulation (1). There currently exists no test that can noninvasively detect this loss of pulmonary microcirculation. The monocrotaline model of PAH, although lacking the intimal proliferation of human PAH, is similarly associated with medial hypertrophy with obliteration and loss of pulmonary arterioles $(9,10)$. The observed reduction in ${ }^{99} \mathrm{~m}$ Tc-AM-L uptake in PAH could, therefore, in great part be caused by reduced pulmonary vascular surface, with loss of adrenomedullin receptors. We cannot, however, rule out a contribution by reduced adrenomedullin receptor affinity.

Previous studies have used the basic amine $\mathrm{N}-\mathrm{N}-\mathrm{N}^{\prime}-$ trimethyl- $N^{\prime}$ (2-hydroxy-3-methyl-5-iodobenzyl)-1,3 propanediamine labeled with radioactive iodine ( ${ }^{123}$ I-HIPDM) for lung imaging $(11,12) .{ }^{123}$ I-HIPDM is extracted by the lungs and, contrary to ${ }^{99 \mathrm{~m} T c-A M-L}$, displayed increased retention in a model of pulmonary hypertension induced by pulmonary vein banding (11). ${ }^{123}$ I-HIPDM is a lipophilic amine that concentrates in lung mitochondria (12) by a receptor-independent process. Although ${ }^{123}$ I-HIPDM has been considered for its potential as a lung vascular imaging agent, it has not been further developed.

The adrenomedullin receptor is a heterodimeric G-protein-coupled receptor composed of 2 components, CLR and RAMP2 (13). The $\mathrm{AM}_{1}$ receptor subtype is composed of CLR-RAMP2, and the $\mathrm{AM}_{2}$ receptor subtype is composed of CLR-RAMP3. These receptors, compared with other related peptides such as the calcitonin gene-related peptide, are distinguished by the greater selectivity of the $\mathrm{AM}_{1}$ subtype for adrenomedullin (14). Using dog lung homogenates, we have characterized 1 high-affinity binding site for AM-L, and using calcitonin family peptides, we determined the binding site to be the $\mathrm{AM}_{1}$ receptor subtype (CLR-RAMP2) (15).

Large-scale analysis of the human and mouse transcriptomes revealed that RAMP2 was relatively equally distributed among most tissues, with the notable exception of high expression levels in the lungs (16). Human and rat lungs indeed contain a high density of specific adrenomedullin binding sites $(4,5)$, mostly distributed on the vascular endothelium. This high density is concordant with studies demonstrating that the lung is an important site for circu- lating adrenomedullin clearance $(2,3)$. Acute lung injury in a sepsis model is associated with markedly increased circulating adrenomedullin levels with concomitant 95\% reduction in lung RAMP2 expression, suggesting that reduced lung binding and clearance could contribute to the increased plasma levels (17). In the current study, we also evaluated lung RAMP2 protein expression and found that it was markedly reduced by about $80 \%$, consistent with the approximate $70 \%$ reduction in lung uptake that we found and with the increased (doubling) of plasma ${ }^{99 \mathrm{~m}} \mathrm{Tc}-$ AM-L levels in PAH.

The monocrotaline model of lung injury with PAH is not selective to pulmonary circulation. Another organ sensitive to the effect of monocrotaline is the kidney, and previous studies have used monocrotaline injection as a model of renal injury (18). Although this study was not designed to evaluate kidney function, we found that monocrotaline resulted in reduced kidney uptake of ${ }^{99 \mathrm{~m}} \mathrm{Tc}-\mathrm{AM}-\mathrm{L}$ by about $50 \%$. This suggests that the loss of kidney adrenomedullin uptake could be used to evaluate kidney damage in this model, but further studies specifically evaluating the kidney adrenomedullin system in this model and other more relevant kidney disease models are required. The observed increase in liver and heart uptake of ${ }^{99 \mathrm{~m} T c-A M-L}$ could be a direct consequence of increased ${ }^{99 \mathrm{~m}} \mathrm{Tc}-\mathrm{AM}-\mathrm{L}$ plasma levels secondary to reduced lung and kidney clearance with greater compensatory liver elimination. Of more relevance to PAH, however, was that ${ }^{99 \mathrm{~m}} \mathrm{Tc}-\mathrm{AM}-\mathrm{L}$ uptake by the heart was increased in PAH and that the right ventricular uptake correlated with the severity of right ventricular hypertrophy. The heart uptake of ${ }^{99 \mathrm{~m} T c-A M-L}$ was, however, low-even in PAH - and the increase could not be detected in vivo by the $\gamma$-camera. These results are nevertheless consistent with studies in rat models of pressure- or volume-induced left ventricular hypertrophy that have demonstrated an evident increase of adrenomedullin receptor expression in the heart $(19,20)$. Whether adrenomedullin receptor expression could be used to detect right ventricular hypertrophy in a larger animal model or in human subjects will be evaluated in future studies.

The current study has some limitations. The findings of the current study in the monocrotaline model of PAH cannot be generalized to all forms of pulmonary hypertension and will require validation in other pathologic models to determine the sensitivity and specificity of this approach for the diagnosis of disorders of pulmonary circulation.

\section{CONCLUSION}

Pulmonary uptake of ${ }^{99 \mathrm{~m}} \mathrm{Tc}-\mathrm{AM}-\mathrm{L}$ is reduced in monocrotaline-induced pulmonary vascular disease and can be detected in vivo using a nuclear camera. This novel molecular imaging agent could potentially be used to diagnose PAH and other disorders of pulmonary circulation associated with reduced biologic expression or function of the adrenomedullin receptor. 


\section{ACKNOWLEDGMENTS}

This study was supported in part by the program of intellectual property management from the Canadian Institutes of Health Research, Ottawa, and by PulmoScience Inc., Montreal, Canada.

\section{REFERENCES}

1. McLaughlin VV, McGoon MD. Pulmonary arterial hypertension. Circulation. 2006;114:1417-1431.

2. Dschietzig T, Azad HA, Asswad L, et al. The adrenomedullin receptor acts as clearance receptor in pulmonary circulation. Biochem Biophys Res Commun. 2002;294:315-318.

3. Dupuis J, Caron A, Ruel N. Biodistribution, plasma kinetics and quantification of single-pass pulmonary clearance of adrenomedullin. Clin Sci (Lond). 2005; 109:97-102.

4. Martinez A, Miller MJ, Catt KJ, Cuttitta F. Adrenomedullin receptor expression in human lung and in pulmonary tumors. J Histochem Cytochem. 1997;45:159164.

5. Owji AA, Smith DM, Coppock HA, et al. An abundant and specific binding site for the novel vasodilator adrenomedullin in the rat. Endocrinology. 1995; 136:2127-2134.

6. Harel F, Fu Y, Nguyen QT, et al. Use of adrenomedullin derivatives for molecular imaging of pulmonary circulation. J Nucl Med. 2008;49:18691874 .

7. Juaneda C, Dumont Y, Chabot J-G, Fournier A, Quirion R. Adrenomedullin receptor binding sites in rat brain and peripheral tissues. Eur J Pharmacol. 2003;474:165-174.

8. Hay DL, Howitt SG, Conner AC, Schindler M, Smith DM, Poyner DR. CL/ RAMP2 and CL/RAMP3 produce pharmacologically distinct adrenomedullin receptors: a comparison effects of adrenomedullin(22-52), CGRP(8-37) and BIBN4096BS. Br J Pharmacol. 2003;140:477-486.
9. Reindel JF, Ganey PE, Wagner JG, Slocombe RF, Roth RA. Development of morphologic, hemodynamic, and biochemical changes in lungs of rats given monocrotaline pyrrole. Toxicol Appl Pharmacol. 1990;106:179-200.

10. Zhao YD, Courtman DW, Deng Y, Kugathasan L, Zhang Q, Stewart DJ. Rescue of monocrotaline-induced pulmonary arterial hypertension using bone marrowderived endothelial-like progenitor cells: efficacy of combined cell and eNOS gene therapy in established disease. Circ Res. 2005;96:442-450.

11. Miniati M, Paci A, Cocci F, Ciarimboli G, Monti S, Pistolesi M. Mitochondria act as a reservoir for the basic amine HIPDM in the lung. Eur Respir J. 1996;9:2306-2312.

12. Shih W-J, Cottrill CM, Coupal JJ, O'Connor W, Kung HF, Ryo UY. Iodine-123HIPDM lung imaging in pulmonary vein-banded pulmonary hypertension. $J$ Nucl Med. 1990;31:668-673.

13. Gibbons C, Dackor R, Dunworth W, Fritz-Six K, Caron KM. Receptor activitymodifying proteins: RAMPing up adrenomedullin signaling. Mol Endocrinol. 2007;21:783-796.

14. Muff R, Born W, Fischer JA. Adrenomedullin selectivity of calcitonin-like receptor/ receptor activity modifying proteins. Hypertens Res. 2003;26(suppl):S3-S8.

15. Fu Y, Létourneau M, Dupuis J, Fournier A. Characterization of the binding sites for the adrenomedullin in the lungs [abstract]. Biopolymers. 2007;88:558.

16. Su AI, Cooke MP, Ching KA, et al. Large-scale analysis of the human and mouse transcriptomes. Proc Natl Acad Sci USA. 2002;99:4465-4470.

17. Ono Y, Okano I, Kojima M, Okada K, Kangawa K. Decreased gene expression of adrenomedullin receptor in mouse lungs during sepsis. Biochem Biophys Res Commun. 2000;271:197-202.

18. Kurozumi T, Tanaka K, Kido M, Shoyama Y. Monocrotaline-induced renal lesions. Exp Mol Pathol. 1983;39:377-386.

19. Yoshihara F, Nishikimi T, Okano I, et al. Upregulation of intracardiac adrenomedullin and its receptor system in rats with volume overload-induced cardiac hypertrophy. Regul Pept. 2005;127:239-244.

20. Wang X, Nishikimi T, Akimoto K, Tadokoro K, Mori Y, Minamino N. Upregulation of ligand, receptor system, and amidating activity of adrenomedullin in left ventricular hypertrophy of severely hypertensive rats: effects of angiotensin-converting enzyme inhibitors and diuretic. J Hypertens. 2003; 21:1171-1181 